\title{
Specimens of Copablepharon fuscum Troubridge and Crabo 1995 (Lepidoptera: Noctuidae) in the Oregon State Arthropod Collection
}

\section{Paul C. Hammond}

Oregon State Arthropod Collection, OSU Department of Integrative Biology,

Corvallis, OR. 97331; copablepharon@gmail.com

Cite this work as:

Hammond, P.C. 2019. Specimens of Copablepharon fuscum Troubridge and Crabo 1995 (Lepidoptera: Noctuidae) in the Oregon State Arthropod Collection. Catalog of the Oregon State Arthropod Collection, 3 (2).

DOI: http://dx.doi.org/10.5399/osu/cat osac.3.2.4598.

This brief catalog entry documents two specimens of $C$. fuscum, one of which is a paratype, deposited into the collection in 1995 by the collector: Lars G. Crabo.

Copablepharon fuscum is endemic to coastal sand dunes with its larval food plant, yellow sand verbena, Abronia latifolia, in southwestern British Columbia and northwestern Washington (Lafontaine et al. 2004). It is potentially endangered due to habitat loss from development, dune stabilization, and suppression of the food plant by invasive plant species such as exotic European beach grass (Crabo, Hammond and Shepard, 2018).

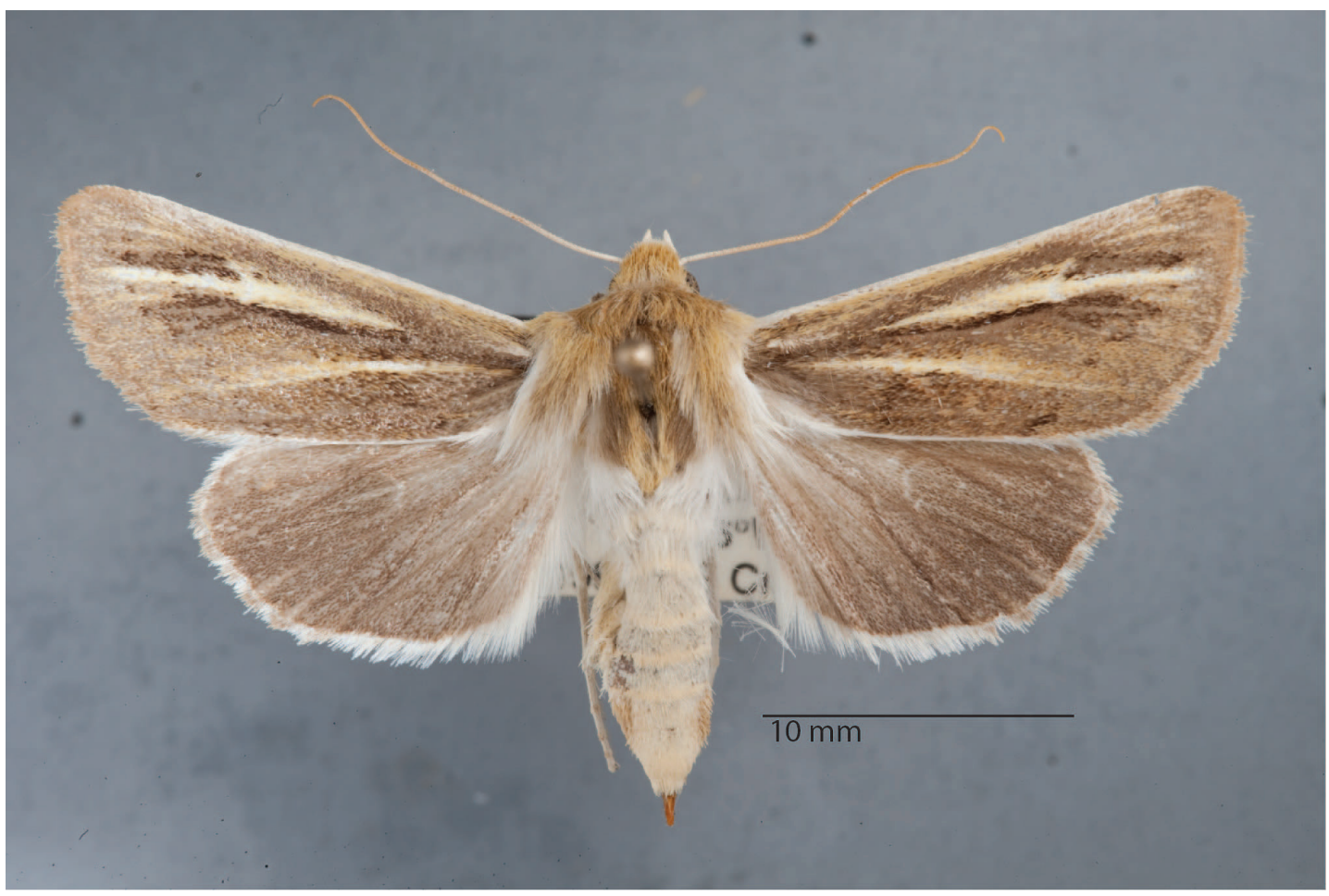

Figure 1. OSAC Specimen \# 0000632995. PARATYPE; female; USA: Washington, Island County, Deception Pass State Park, Ocean Sand Dunes near Cranberry Lake. Elevation: $<20$ ft $48.38^{\circ} \mathrm{N} 122.66^{\circ} \mathrm{W}$; 26 May 1995; leg: Lars G. Crabo; http:/ / osac.oregonstate.edu/sp/osac 0000632995 


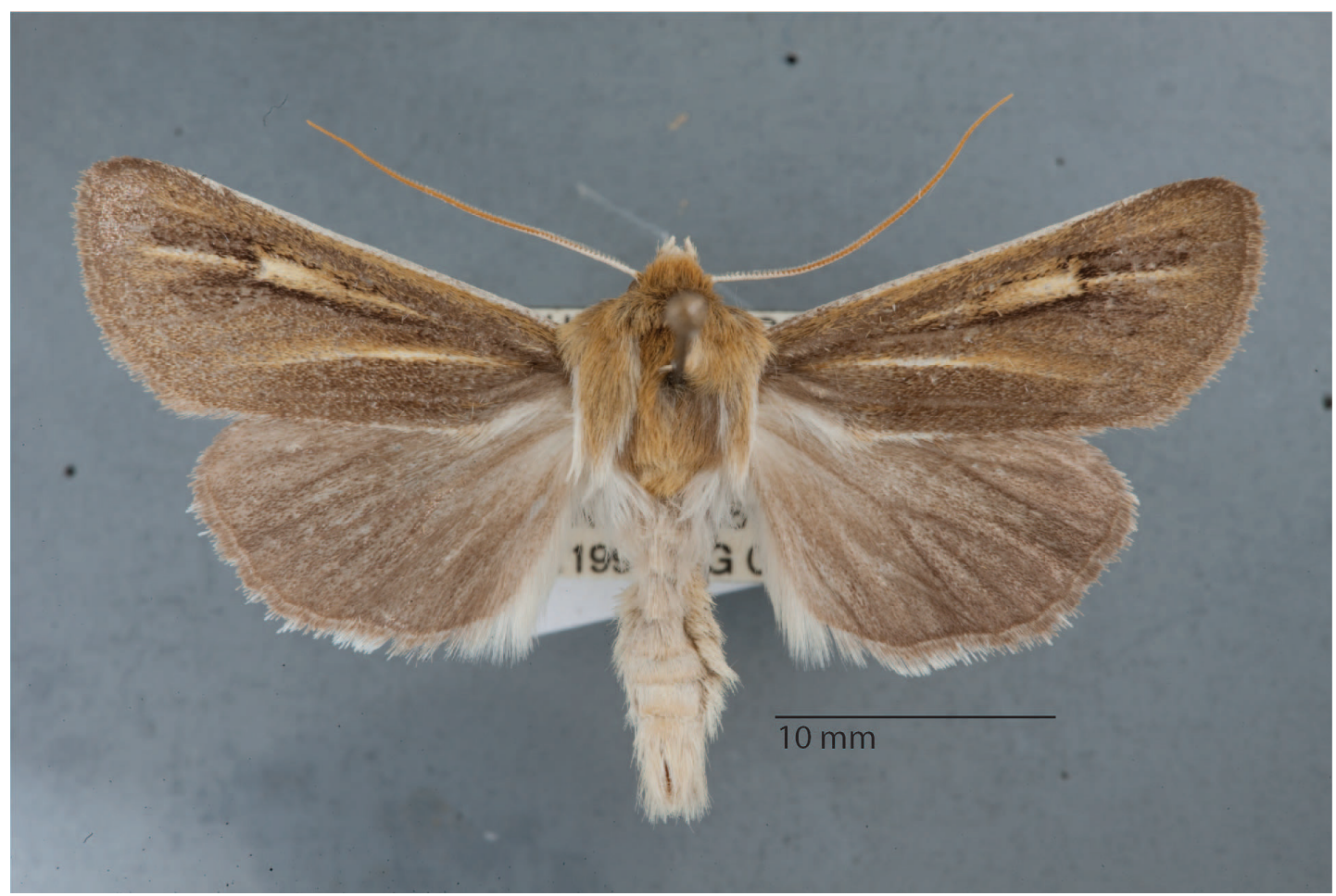

Figure 2. OSAC Specimen \# 0000131594; male; USA: Washington, Island County, Deception Pass State Park, Ocean Sand Dunes near Cranberry Lake. Elevation: < 20ft; $48.38^{\circ}$ N 122.66 W; 19 May 1995; leg: Lars G. Crabo http:// osac.oregonstate.edu/sp/OSAC 0000131594

\section{References}

Crabo, L.G., P.C. Hammond, J.H. Shepard. (2018). Species Page: Copablepharon fuscum. In: Moths of the Pacific Northwest. L.C. Crabo, M.A. Peterson, R. Zack, P.C. Hammond, J.H. Shepard and M. Davis. http: / / pnwmoths.biol.wwu.edu / [accessed 2018].

Lafontaine J.D., Crabo L.G., Fauske G.A. (2004). Genus Copablepharon Harvey. The Moths of North America Noctuoidea, Noctuidae (part) Fascicle 27.1: 146-180.

Troubridge J.T., Crabo L.G. (1995). New species of Copablepharon (Lepidoptera: Noctuidae) from British Columbia and Washington. Journal of the Entomological Society of British Columbia 92: 87-90. 